\title{
Infralevator leiomyoma
}

\author{
A. Kamrava $\cdot$ M. A. Abbas • D. S. Katz
}

Received: 2 March 2009/ Accepted: 9 October 2010/Published online: 18 November 2010

(C) Springer-Verlag 2010

A 39-year-old woman presented with chronic and cyclical anorectal pain. A right ischiorectal mass was palpable but there were no skin changes. Ultrasound examination showed a solid mass extending from within the levator plate (Fig. 1). Computed tomography confirmed a $5.7 \times$ $3.2 \times 5.0 \mathrm{~cm}$ mass (Fig. 2). The patient underwent a pararectal excision of the mass (Fig. 3). On histological

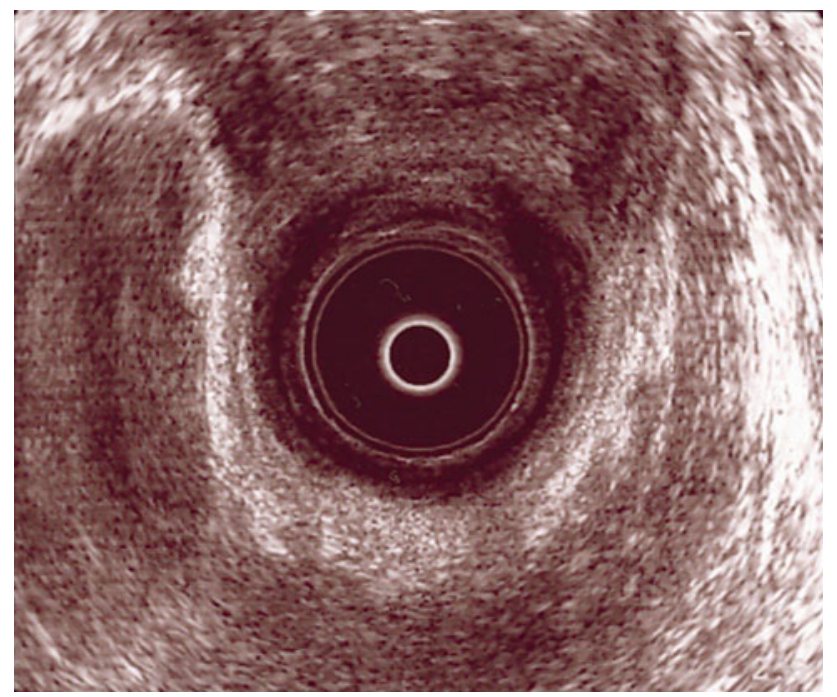

Fig. 1 Ultrasound examination showing a solid mass extending from within the levator plate

A. Kamrava $(\bowtie) \cdot$ M. A. Abbas

Kaiser Permanente Hospital, Los Angeles, CA, USA

e-mail: allen.kamrava@gmail.com

D. S. Katz

Winthrop-University Hospital, New York, NY, USA

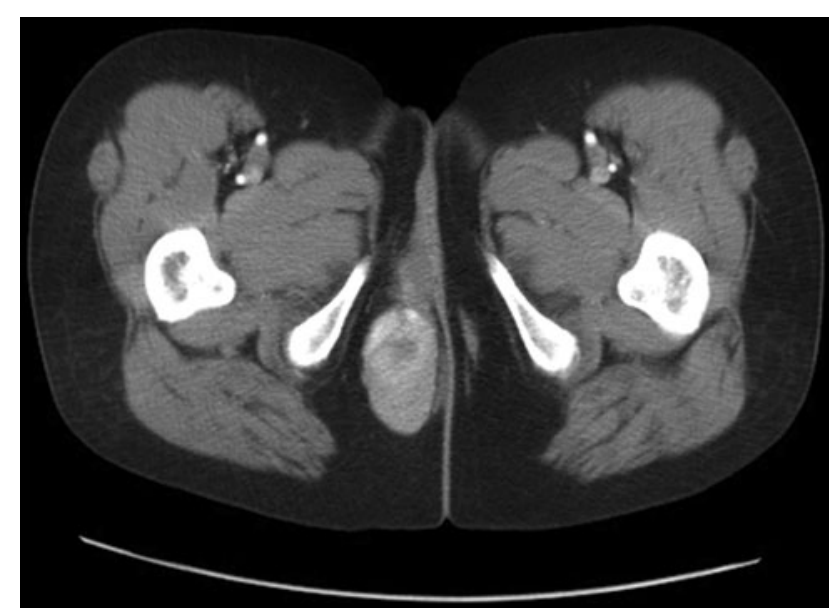

Fig. 2 Computed tomography confirmed a $5.7 \times 3.2 \times 5.0 \mathrm{~cm}$ mass

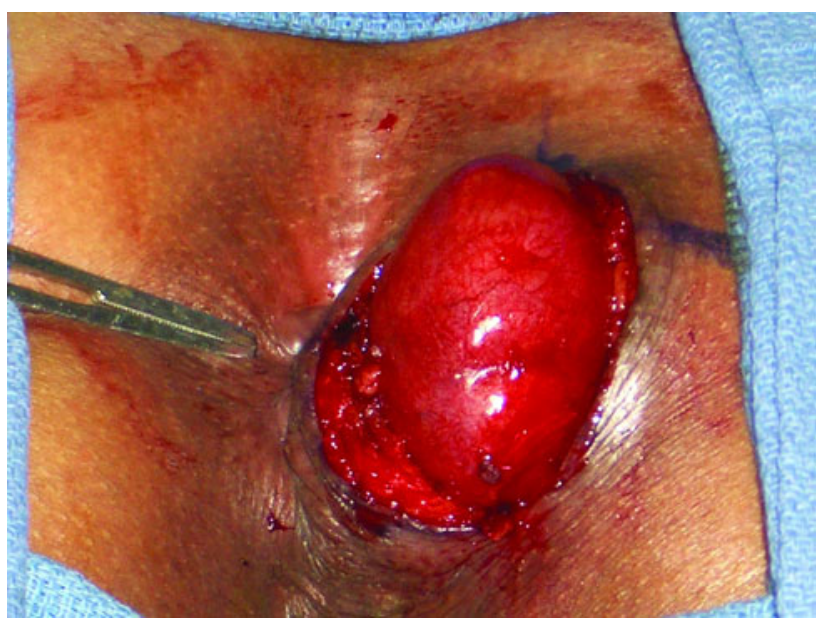

Fig. 3 Intraoperative image of the tumor protruding from the anal verge 


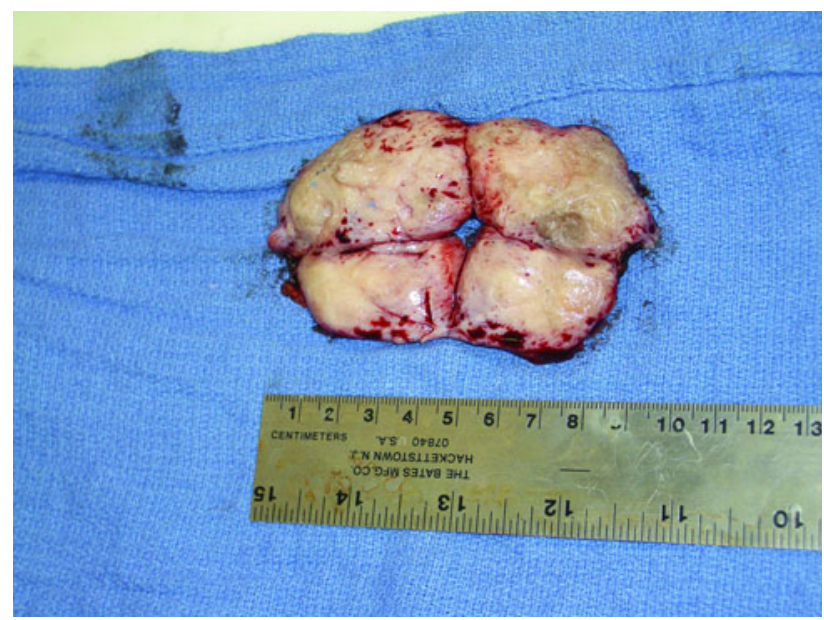

Fig. 4 Specimen of the pararectal excision of the mass revealing a leiomyoma

examination revealed a leiomyoma (Fig. 4). The inferior aspect of the levator ani muscle is an uncommon location for a leiomyoma. 